\title{
Age, sex, and comorbidities predict ICU admission or mortality in cases with SARS- CoV2 infection: a population-based cohort study
}

\author{
Filipe S. Cardoso ${ }^{1}$, Ana L. Papoila ${ }^{2}$, Rita Sá Machado ${ }^{3}$ and Pedro Fidalgo ${ }^{4^{*}}$ (D)
}

\section{Dear Editor,}

Previous studies have identified risk factors for severe acute respiratory syndrome coronavirus 2 (SARS-CoV2) severe outcomes preferentially among hospitalized patients; therefore, they may have understated the denominator of such estimations $[1,2]$. We aimed to determine pre-hospital risk factors and estimate individual probabilities of SARS-CoV2 severe outcomes among a nationwide cohort of cases of SARS-CoV2 infection, including those with and without hospitalization.

This was a retrospective analysis from a nationwide prospective registry, including confirmed (nasal/pharynx swab real-time polymerase chain reaction) cases of SARS-CoV2 infection notified to the DirectorateGeneral of Health from March 02 until April 21, 2020, in Portugal. Primary endpoint was a composite of ICU admission or all-cause mortality until April 21. Multivariable analysis was performed with logistic regression. Internal validation was performed with bootstrapping. Models' performance was studied with calibration plots, $c$-statistic, and Brier score [3, 4]. Significance level was $\alpha=0.05$. Informed consent was waived due to the use of anonymized data and the current state of public health emergency.

Overall, 18,647 cases were included in our analyses, following exclusion of 1623 (8.0\%) cases without hospital admission status and $23(0.1 \%)$ cases without outcome status.

\footnotetext{
* Correspondence: pedrofidalgo.com@gmail.com

${ }^{4}$ Intensive Care Unit, São Francisco Xavier Hospital, Western Lisbon Hospital Center, Estrada do Forte do Alto do Duque, 1449-005 Lisbon, Portugal

Full list of author information is available at the end of the article
}

Among all cases, median (IQR) age was 50 (36-66) years (Table 1). Male sex accounted for 7701 (41.3\%) of all cases. While 15,651 (83.9\%) cases did not have any comorbidity, the remainder of cases had the following number of comorbidities: one in 2213 (11.9\%) cases, 2 in $600(3.2 \%)$ cases, and $\geq 3$ in $183(1.0 \%)$ cases.

Median (IQR) follow-up was 27 (19-33) days. Overall, $2952(15.8 \%)$ or $258(1.4 \%)$ cases required hospital or ICU admission, respectively. All-cause mortality occurred in $456(2.4 \%)$ cases. Among these cases, 330 (72.4\%) died following hospital admission and 126 (27.6\%) died without any reported hospital admission.

There were 687 (3.7\%) cases admitted to the ICU or deceased (Table 1). Cases with ICU admission or nonsurvivors had higher median age ( 80 vs. 49 years; $P<$ $0.001)$ and were more frequently men $(54.7 \%$ vs. $40.8 \%$; $P<0.001)$ than those that were not admitted to the ICU and survived.

Cases with ICU admission or non-survivors had more frequently any comorbidity than those that were not admitted to the ICU and survived $(56.6 \%$ vs. $14.5 \%$; $P<$ 0.001). All types of comorbidities were more frequently reported in cases with ICU admission or non-survivors than those that were not admitted to the ICU and survived.

In multivariable analysis with logistic regression, higher age (aOR 1.065), male sex (aOR 1.896), or higher number of comorbidities (aOR 2.953 if one vs. aOR 3.568 if 2 vs. aOR 6.002 if $\geq 3$; $P<0.001$ for all comparisons) were associated with higher risk of ICU admission or all-cause mortality (Table 2).

The model's calibration plot showed a very good predictive performance up to estimated probabilities of 
Table 1 Baseline characteristics stratified by intensive care unit admission or all-cause mortality status

\begin{tabular}{|c|c|c|c|c|}
\hline $\begin{array}{l}\text { Characteristic } \\
\boldsymbol{n}(\%) \text { or median (IQR) }\end{array}$ & Overall $(\boldsymbol{n}=18,647)$ & ICU or deceased $(\boldsymbol{n}=687)$ & No ICU and survived $(\boldsymbol{n}=17,960)$ & $P^{*}$ \\
\hline Age (years) & $50(36-66)$ & $80(69-87)$ & $49(35-64)$ & $<0.001$ \\
\hline Sex (male) & 7701 (41.3\%) & $376(54.7 \%)$ & $7325(40.8 \%)$ & $<0.001$ \\
\hline Number of comorbidities & & & & $<0.001$ \\
\hline None & $15,651(83.9 \%)$ & $298(43.4 \%)$ & $15,353(85.5 \%)$ & \\
\hline 1 & $2213(11.9 \%)$ & $233(33.9 \%)$ & $1980(11.0 \%)$ & \\
\hline 2 & $600(3.2 \%)$ & $103(15.0 \%)$ & $497(2.8 \%)$ & \\
\hline$\geq 3$ & $183(1.0 \%)$ & $53(7.7 \%)$ & $130(0.7 \%)$ & \\
\hline \multicolumn{5}{|l|}{ Types of comorbidities } \\
\hline Diabetes mellitus & $1056(5.7 \%)$ & $128(18.6 \%)$ & $928(5.2 \%)$ & $<0.001$ \\
\hline Respiratory & $841(4.5 \%)$ & $94(13.7 \%)$ & $747(4.2 \%)$ & $<0.001$ \\
\hline Neurological/muscular & 730 (3.9\%) & $136(19.8 \%)$ & $594(3.3 \%)$ & $<0.001$ \\
\hline Malignancy & $568(3.0 \%)$ & $63(9.2 \%)$ & $505(2.8 \%)$ & $<0.001$ \\
\hline Cardiovascular/kidney & $410(2.2 \%)$ & $131(19.1 \%)$ & $279(1.6 \%)$ & $<0.001$ \\
\hline Hematological & $201(1.1 \%)$ & $35(5.1 \%)$ & $166(0.9 \%)$ & $<0.001$ \\
\hline Liver & $102(0.5 \%)$ & $11(1.6 \%)$ & $91(0.5 \%)$ & $<0.001$ \\
\hline HIV infection & $99(0.5 \%)$ & $13(1.9 \%)$ & $86(0.5 \%)$ & $<0.001$ \\
\hline Hospital admission & $2952(15.8 \%)$ & $561(81.7 \%)$ & $2391(13.3 \%)$ & $<0.001$ \\
\hline $\begin{array}{l}\text { Time from symptoms onset to hospital admission (days) } \\
(n=1910)\end{array}$ & $4(2-7)$ & $4(2-8)$ & $4(2-7)$ & 0.37 \\
\hline Follow-up (days) $(n=14,470)$ & $27(19-33)$ & $27(20-34)$ & $27(19-33)$ & 0.13 \\
\hline
\end{tabular}

IQR interquartile range, HIV human immunodeficiency virus, ICU intensive care unit

${ }^{*}$ Chi-square (categorical variables) or Mann-Whitney (continuous variables) tests $(a=0.05)$ 
Table $\mathbf{2}$ Independent risk factors for intensive care unit admission or all-cause mortality

\begin{tabular}{|c|c|c|c|c|c|c|c|c|}
\hline \multicolumn{9}{|l|}{ Risk factors } \\
\hline \multicolumn{2}{|l|}{ Characteristic } & \multicolumn{2}{|c|}{ Unadjusted OR (95\%CI) } & \multicolumn{2}{|c|}{ Adjusted OR (95\%Cl) } & \multicolumn{3}{|l|}{$P$} \\
\hline \multicolumn{2}{|l|}{ Age (years) } & \multicolumn{2}{|c|}{$1.071(1.066-1.076)$} & \multicolumn{2}{|c|}{$1.065(1.059-1.071)$} & \multicolumn{3}{|l|}{$<0.001$} \\
\hline \multicolumn{2}{|l|}{ Sex (male) } & \multicolumn{2}{|c|}{$1.755(1.506-2.046)$} & \multicolumn{2}{|c|}{$1.896(1.608-2.236)$} & \multicolumn{3}{|l|}{$<0.001$} \\
\hline \multicolumn{4}{|c|}{ Number of comorbidities } & & & \multicolumn{3}{|l|}{$<0.001$} \\
\hline \multicolumn{9}{|l|}{ None } \\
\hline \multicolumn{2}{|l|}{1} & \multicolumn{2}{|c|}{$6.063(5.076-7.242)$} & \multicolumn{2}{|c|}{$2.953(2.450-3.560)$} & \multicolumn{3}{|l|}{$<0.001$} \\
\hline \multicolumn{2}{|l|}{2} & \multicolumn{2}{|c|}{$10.677(8.389-13.589)$} & \multicolumn{2}{|c|}{$3.568(2.768-4.599)$} & \multicolumn{3}{|l|}{$<0.001$} \\
\hline \multicolumn{2}{|l|}{$\geq 3$} & \multicolumn{2}{|c|}{$21.004(14.960-29.491)$} & \multicolumn{2}{|c|}{$6.002(4.206-8.566)$} & \multicolumn{3}{|l|}{$<0.001$} \\
\hline \multicolumn{9}{|c|}{ Examples of predicted probabilities } \\
\hline Age (years) & 20 & & 40 & & 60 & & 80 & \\
\hline Sex & Male & Female & Male & Female & Male & Female & Male & Female \\
\hline \multicolumn{9}{|c|}{ Number of comorbidities } \\
\hline 0 & 0.002 & 0.001 & 0.007 & 0.004 & 0.025 & 0.014 & 0.083 & 0.046 \\
\hline 1 & 0.006 & 0.003 & 0.021 & 0.011 & 0.071 & 0.039 & 0.211 & 0.124 \\
\hline 2 & 0.007 & 0.004 & 0.026 & 0.014 & 0.084 & 0.046 & 0.244 & 0.146 \\
\hline$\geq 3$ & 0.012 & 0.007 & 0.042 & 0.023 & 0.134 & 0.075 & 0.351 & 0.222 \\
\hline
\end{tabular}

OR risk ratio, $95 \% \mathrm{Cl} 95 \%$ confidence interval, ICU intensive care unit

Model: $n$ total $=18,647, n$ events of ICU admission or all-cause mortality $=687$; $c$-statistic of $0.876(95 \% \mathrm{Cl} 0.866-0.887)$; Brier score of 0.0322

Probability of intensive care unit admission or all-cause mortality $=e^{y} /\left(e^{y}+1\right)$

$y=-8.053+0.0627^{*}$ Age (years) $+0.6374 * \mathrm{Sex}$ (male as one or female as zero) $+A$ or $B$ or $C(A=1.0786$ if one comorbidity; $B=1.2668$ if 2 comorbidities; $C=1.7847$

if $\geq 3$ comorbidities)

0.20 , after which threshold it overestimated such probabilities as they became less frequent. After bootstrapping (slope shrinkage estimate of 0.9959), the predictive equation was the following: $e^{y} /\left(1+e^{y}\right)$ where $y=-$ $8.053+0.0627 *$ Age (years) $+0.6374 *$ Sex (male as one or female as zero $)+A$ or $B$ or $C(A=1.0786$ if one comorbidity; $B=1.2668$ if 2 comorbidities; $C=1.7847$ if $\geq 3$ comorbidities). This predictive model had a bootstrapped $c$-statistic of 0.876 (95\% confidence interval 0.864-0.886) and a Brier score of 0.0323 .

Among cases with SARS-CoV2 infection at an early phase of the epidemic in Portugal, pre-hospital characteristics like age, sex, and the number of comorbidities were useful to predict ICU admission or all-cause mortality [5]. These findings may inform health policies designed to protect specific subgroups of the population and project allocation of health resources, especially while measures of containment are being eased in many countries.

\section{Abbreviations}

aOR: Adjusted odds ratio; COVID-19: Coronavirus disease; ICU: Intensive care unit; IQR: Interquartile range; SARS-CoV2: Severe acute respiratory syndrome coronavirus 2

\section{Acknowledgements}

The authors would like to acknowledge the Portuguese Directorate-General of Health and all staff of the Portuguese National Health System.

\section{Authors' contributions}

Dr. Cardoso is the guarantor of the paper, taking responsibility for the integrity of the content of the manuscript as a whole, from inception to published article. Dr. Cardoso conceived and designed the study, performed statistical and data analyses, drafted the manuscript, revised the manuscript, and provided final approval. Prof Papoila provided significant contribution to data analyses and interpretation, revised the manuscript, and provided final approval. Dr. Machado provided significant contribution to data acquisition, contributed to the data analysis and interpretation, revised the manuscript, and provided final approval. Dr. Fidalgo contributed to the conception and design of the study and data analysis and interpretation, contributed to drafting and revision of the manuscript, and provided final approval. The manuscript has been reviewed and approved by all authors.

\section{Funding}

The authors received no funding at all pertaining to this study.

\section{Availability of data and materials}

The datasets generated and/or analyzed during the current study are not publicly available due to confidentiality but are available from the corresponding author on reasonable request.

Ethics approval and consent to participate

This study was approved by the Ethics Committee at Curry Cabral Hospital, Central Lisbon University Hospital Center, Lisbon, Portugal. Informed consent was waived due to the use of anonymized data and the current public health state of emergency.

\section{Consent for publication}

Not applicable.

\section{Competing interests}

The authors declare that they have no competing interests.

\section{Author details}

${ }^{1}$ Intensive Care Unit, Curry Cabral Hospital, Central Lisbon University Hospital Center, Nova Medical School, Nova University, Lisbon, Portugal. 
${ }^{2}$ Epidemiology and Statistics Unit, Research Center, Central Lisbon University Hospital Center, Nova Medical School, Nova University, Center of Statistics and its Applications, Lisbon University, Lisbon, Portugal. ${ }^{3}$ Directorate-General of Health, Division of Epidemiology and Statistics, Lisbon, Portugal. ${ }^{4}$ Intensive Care Unit, São Francisco Xavier Hospital, Western Lisbon Hospital Center, Estrada do Forte do Alto do Duque, 1449-005 Lisbon, Portugal.

Received: 6 July 2020 Accepted: 12 July 2020

Published online: 28 July 2020

\section{References}

1. Guan WJ, Liang WH, Zhao Y, Liang HR, Chen ZS, Li YM, et al. Comorbidity and its impact on 1590 patients with COVID-19 in China: a nationwide analysis. Eur Respir J. 2020;55(5):2000547.

2. Yang J, Zheng Y, Gou X, et al. Prevalence of comorbidities and its effects in cases infected with SARS-CoV-2: a systematic review and meta-analysis. Int J Infect Dis. 2020;94:91-5.

3. Harrell FE. Regression modelling strategies: with applications to linear models, logistic regression, and survival analysis. New York: Springer; 2015.

4. Firth D. Bias reduction of maximum likelihood estimates. Biometrika. 1993; 80:27-38.

5. Banerjee A, Pasea L, Harris S, Gonzalez-Izquierdo A, Torralbo A, Shallcross L, et al. Estimating excess 1-year mortality associated with the COVID-19 pandemic according to underlying conditions and age: a population-based cohort study. Lancet. 2020;395(10238):1715-25.

\section{Publisher's Note}

Springer Nature remains neutral with regard to jurisdictional claims in published maps and institutional affiliations.

- fast, convenient online submission

- thorough peer review by experienced researchers in your field

- rapid publication on acceptance

- support for research data, including large and complex data types

- gold Open Access which fosters wider collaboration and increased citations

- maximum visibility for your research: over $100 \mathrm{M}$ website views per year

At $\mathrm{BMC}$, research is always in progress.

Learn more biomedcentral.com/submissions 